KINDERGARTEN: Journal of Islamic Early Childhood Education

Homepage: bttp:/ / ejournal.uin-suska.ac.id/index.php/KINDERGARTEN

Vol. 2, No. 2 November 2019, Hal 65-77

Email:jcie.piand@uin-suska.ac.id

p-ISSN 2621-0339

e-ISSN 2621-0770

\title{
Pengaruh Kegiatan Mewarnai Gambar terhadap Kemampuan Motorik Halus Anak Kelompok B di Pendidikan Anak Usia Dini Bukit Selanjut Kecamatan Kelayang Kabupaten Indragiri Hulu
}

\author{
Ilham Kurnia \\ Universitas Islam Negeri Sunan Kalijaga Yogyakarta \\ Ilhamku1793@gmail.com
}

\begin{abstract}
.
This study aims to determine the effect of image coloring activity on fine motor group $B$ children in PAUD Bukit Selanjut Kelayang Sub-district Indragiri Hulu Regency. This research is an experimental research using one-group pretest-posttest design to know comparison before and after treatment. Subjects of this study amounted to 7 children, with the objects is the influence of picture coloring activities on motor fine capabilities of group B Children in PAUD Bukit Selanjut Kelayang Sub-district Indragiri Hulu Regency. The population of this research is students in kindergarten PAUD Bukit Selanjut Kelayang Sub-district Indragiri Hulu Regency amounting to 13 children, whith a sample of 7 children consisting 4 from a man dan 3 from a woman. The sample is done by purposive sampling technique, that is by determining the sample through certain consideration. Data collection techniques used are test, observation and documentation. While the technique of data analysis using t-test test using SPSS Windows ver. 17. The results showed that $t_{\text {bitung }}=27,000$ with Sig $=0,000$. Because sig value $<0,05$ and $t_{\text {hitung }}=27,000$ bigger than $t_{\text {tabel }}=2,447$, it can be concluded that there is significant influence after giving treatment in picture coloring activity. so $\mathrm{Ho}$ is rejected $\mathrm{Ha}$ accepted which means there is influence before and after being treated to fine motor abilities of children. The influence of picture coloring activity on fine motor ability of group B children in PAUD Bukit Selanjut Kelayang Sub-district Indragiri Hulu Regency is 56,25\% (in medium category).
\end{abstract}

Keywords: Smooth Motor Capability, Picture Coloring Activity

\begin{abstract}
ABSTRAK.
Penelitian ini bertujuan untuk mengetahui pengarub kegiatan mewarnai gambar terbadap kemampuan motorik halus anak kelompok B di PAUD Bukit Selanjut Kecamatan Kelayang Kabupaten Indragiri Hulu. Penelitian ini adalah penelitian eksperimen yang menggunakan one-group pretest-posttest design untuk mengetahui perbandingan sebelum dan sesudah diberi perlakuan. Subjek penelitian ini berjumlah 7 orang anak, dengan objek, pengarub kegiatan mewarnai gambar terhadap kemampuan motorik halus anak kelompok B di PAUD Bukit Selanjut Kecamatan Kelayang Kabupaten Indragiri Hulu. Populasi penelitian ini adalah anak didik di PAUD Bukit Selanjut Kecamatan Kelayang Kabupaten Indragiri Hulu yang
\end{abstract}


berjumlah 13 anak, dengan sampel 7 orang anak yang terdiri dari 4 Laki-laki dan 3 Perempuan. Sampel dilakukan dengan teknik, purposive sampling, yaitu dengan penentuan sampel melalui pertimbangan tertentu. Teknik pengumpulan data yang digunakan adalah test, observasi dan dokumentasi. Sedangkan teknik analisis data menggunakan uji t-test dengan menggunakan program SPSS Windows ver. 17. Hasil penelitian menunjukekan bahwa $t_{\text {bitung }}=$ 27,000 dengan Sig $=0,000$. Karena nilai sig $<0,05$ dan thitung $=27,000$ lebih besar dari tabel $=2,447$. maka dapat disimpulkan bahwa terdapat pengarub yang signifikan setelah pemberian perlakuan dalam kegiatan mewarnai gambar. Jadi Ho ditolak dan Ha diterima yang berarti terdapat pengaruh sebelum dan sesudah diberi perlakuan terhadap kemampuan motorik halus anak. Pengarub kegiatan mewarnai gambar terbadap kemampuan motorik balus anak kelompok B di PAUD Bukit Selanjut Kecamatan Kelayang Kabupaten Indragiri Hulu sebesar 56,25\% (berada pada kategori sedang).

Kata kunci: Kemampuan Motorik Halus, Kegiatan Mewarnai Gambar

\section{PENDAHULUAN}

Pendidikan merupakan aset yang paling berharga bagi bangsa ini, Itulah sebabnya proses pendidikan diharapkan dapat berjalan secara optimal dan berkualitas. Sementara, inti dari proses pendidikan itu sendiri adalah proses pembelajaran. Dengan demikian, dapatlah dikatakan bahwa keberhasilan dalam meraih fungsi dan tujuan pendidikan nasional sangat bergantung pada keberhasilan guru dalam menjalankan proses pembelajaran yang optimal dan berkualitas (Novan Ardy Wijayani, 2014). Kegiatan belajar-mengajar melibatkan beberapa komponen, yaitu peserta didik, guru (pendidik), tujuan pembelajaran, isi pembelajaran, metode mengajar, media, dan evaluasi. Tujuan pembelajaran adalah perubahan perilaku dan tingkah laku yang positif dari peserta didik setelah mengikuti kegiatan belajar-mengajar.

Sesuai studi pendahuluan yang dilakukan Peneliti di PAUD Bukit Selanjut Kecamatan Kelayang Kabupaten Indragiri Hulu, disana masih ada kekurangan dalam mengembangkan motorik halus anak, yang mana mereka telah menggunakan atau memberikan kegiatan-kegiatan yang berhubungan dengan pengembangan motorik halus seperti menggambar, menempel, menggunting dan mewarnai. Walaupun para guru telah berusaha meningkatkan kinerja mereka agar pembelajaran di PAUD tersebut efektif dan optimal. Namun, masih saja belum menghasilkan proses pembelajaran yang efektif dan optimal. Ini dapat dilihat dari fenomenafenomena berikut; Pertama, Masih ada beberapa peserta didik yang belum mampu mengoles warna pada pola dengan baik. Kedua, Masih ada beberapa peserta didik yang belum mampu memadukan warna pada gambar dengan baik. Ketiga, Masih ada beberapa peserta didik yang belum mampu mengerakkan tangan dengan lentur. Gejala-gejala di atas dikarenakan berbagai macam faktor diantaranya: Pertama, Kurangnya ilmu dari Pendidik akan metode atau strategi untuk merangsang atau menstimulus perkembangan anak, terutama motorik halus. Kedua, 


\section{Ilham Kurnia}

Kurangnya rangsangan atau pemberian stimulus dari orang tua di rumah dalam hal perkembangan anak, terutama motorik halus.

Kegiatan Mewarnai Gambar juga merupakan salah satu alternatif kegiatan pembelajaran yang dapat dilakukan oleh guru di sekolah untuk mengembangkan kemampuan motorik halus khususnya anak kelompok B yaitu usia 5-6 tahun. Berdasarkan identifikasi dan batasan masalah tersebut maka peneliti dapat merumuskan masalah yaitu Apakah ada pengaruh kegiatan mewarnai gambar terhadap kemampuan motorik halus anak kelompok B di PAUD Bukit Selanjut Kecamatan Kelayang Kabupaten Indragiri Hulu?

Dengan tujuan untuk mengetahui ada atau tidaknya pengaruh kegiatan mewarnai gambar terhadap kemampuan motorik halus anak kelompok B di PAUD Bukit Selanjut Kecamatan Kelayang Kabupaten Indragiri Hulu.

Adapun manfaat yang bisa diambil dalam penelitian ini adalah:

1. Untuk anak

Melalui kegiatan mewarnai gambar, diharapkan aspek perkembangan anak dapat tercapai dengan baik, terutama kemampuan motorik halusnya. Selain itu, mempersiapkan anak untuk memasuki jenjang sekolah selanjutnya melalui stimulasi kemampuan motorik halus yang telah diberikan.

2. Untuk guru

Dapat menjadi salah satu masukan, rujukan dan wawasan guru dalam mengembangkan motorik halus anak, khususnya kegiatan mewarnai gambar dengan menggunakan alat yang bervariasi untuk mewarnai gambar, sehingga anak tidak merasa bosan serta meningkatkan kualitas pembelajaran agar lebih baik.

3. Untuk lembaga pendidikan

Sebagai masukan, rujukan dan wawasan dalam upaya meningkatkan sarana dan prasarana dalam meningkatkan kemampuan motorik halus. Selain itu, membantu mengatasi permasalahan yang terdapat di lembaga pedidikan agar lebih baik.

4. Untuk peneliti

Melalui penelitian ini akan dapat menambah wawasan keilmuan dalam aspek perkembangan motorik halus anak usia dini melalui kegiatan mewarnai gambar.

5. Untuk peneliti selanjutnya

Dapat digunakan sebagai referensi tentang kegiatan mewarnai gambar terhadap kemampuan motorik halus anak usia 5-6 tahun.

\section{Kegiatan Mewarnai Gambar}


Menurut Kamus Besar Bahasa Indonesia, ”Mewarnai” merupakan kata kerja yang berasal dari kata dasar "warna", artinya memberi warna; mengecat dan sebagainya; menandai (dengan warna tertentu); mempengaruhi. Dan kata "Gambar" dalam Kamus Besar Bahasa Indonesia yang merupakan kata benda, yang artinya tiruan barang (orang, binatang, tumbuhan, dan sebagainya) yang dibuat dengan coretan pensil dan sebagainya pada kertas dan sebagainya; lukisan. Sedangkan kegiatan mewarnai gambar adalah kegiatan mewarnai yang dilakukan menggunakan berbagai macam media seperti krayon, spidol, pensil warna dan pewarna makanan. Jadi dari beberapa pengertian di atas dapat disimpulkan bahwa kegiatan mewarnai gambar adalah suatu kegiatan memberikan warna pada suatu bidang yang memiliki bentuk baik orang, binatang, tumbuhan dan sebagainya dengan menggunakan pewarna baik spidol, pensil warna, pewarna makanan dan warna lainnya.

Salah satu cara untuk meningkatkan kemampuan motorik halus yaitu melalui kegiatan mewarnai gambar sepertimana dikatakan oleh Adi D. Tilong bahwa kegiatan mewarnai berfungsi sebagai alat pendidikan untuk merangsang perkembangan anak secara keseluruhan. Mewarnai merupakan kegiatan yang sangat penting bagi perkembangan otak anak, terutama kemampuan imajinasinya. Sama halnya dengan menggambar, kegiatan yang satu ini pun sangat menyenangkan bagi anak-anak dari semua kelompok usia. Bahkan, kegiatan mewarnai berfungsi sebagai alat untuk merangsang perkembangan anak secara keseluruhan.

\section{Kemampuan Motorik Halus}

Istilah kemampuan dapat didefinisikan dalam berbagai arti, salah satunya menurut Munandar menjelaskan bahwa kemampuan merupakan daya untuk melakukan suatu tindakan sebagai hasil dari pembawaan dan latihan. Sedangkan Fatkhuromah mengatakan bahwa kemampuan adalah kesanggupan, kecakapan, kekuatan, atau potensi bawaan sejak lahir atau hasil latihan yang dapat digunakan untuk melakukan suatu perbuatan.

Dan motorik menurut Meggit merupakan terjemahan dari kata motor, yaitu: Motor artinya dasar mekanika yang menyebabkan terjadinya suatu gerak. Gerak (movement) adalah suatu aktivitas yang didasari oleh proses motorik. Proses motorik ini melibatkan sebuah sistem pola gerakan yang terkoordinasi (otak, syaraf, otot, dan rangka) dengan proses mental yang sangat kompleks, disebut sebagai proses cipta gerak. Keempat unsur tersebut tidak bisa bekerja secara sendiri-sendiri, melainkan selalu terkoordinasi.

\section{Tingkat pencapaian perkembangan kemampuan motorik halus anak usia 5-6 tahun}


Dalam pengenalan kemampuan motorik halus pada anak harus disesuaikan dengan karakteristik masing-masing usia anak. Mengacu pada Peraturan Menteri Pendidikan Nasional Republik Indonesia Nomor 58 Tahun 2009, Lingkup perkembangan motorik dalam bidang motorik halus. Adapun tingkat pencapaian perkembangan adalah sebagai berikut: Pertama, Menggambar sesuai gagasannya. Kedua, Meniru bentuk. Ketiga, Melakukan eksplorasi dengan berbagai media dan kegiatan. Keempat, Menggunakan alat tulis dengan benar. Kelima, Menggunting sesuai dengan pola. Keenam, Menempel gambar dengan tepat. Ketujuh, Mengekspresikan diri melalui gerakan menggambar secara detail.

Dan mengacu pada Peraturan Menteri Pendidikan dan Kebudayaan No. 137 Tahun 2014 standar tingkat pencapaian kemampuan anak usia 5-6 tahun dalam lingkup perkembangan motorik halus, yaitu: kemampuan dan kelenturan menggunakan jari dan alat untuk mengeksplorasi dan mengekspresikan diri dalam berbagai bentuk.

\section{METODE}

Penelitian ini adalah penelitian eksperimen, yang mana dalam penelitian eksperimen ini menggunakan one-group pretest-posttest design, untuk mengetahui efek sebelum dan sesudah perlakuan. Dengan demikian hasil perlakuan dapat diketahui lebih akurat, karena dapat membandingkan dengan keadaan sebelum diberi perlakuan. Penelitian ini dilakukan pada satu kelompok saja tanpa ada kelompok perbandingan.

\begin{tabular}{|c|c|c|}
\hline Pretest & Variabel bebas & Posttest \\
\hline O1 & $\mathrm{X}$ & O2 \\
\hline
\end{tabular}

Keterangan:
$\mathrm{O}_{1}:$ Nilai Pre-test (sebelum diberikan perlakuan)
$\mathrm{X}:$ Perlakuan Eksperimen (media stick puppets)
$\mathrm{O}_{2}:$ Nilai Post-test (sesudah diberikan perlakuan)

Penelitian ini berlokasi di PAUD Bukit Selanjut Kecamatan Kelayang Kabupaten Indragiri Hulu. Penelitian ini dilaksanakan pada bulan Januari-Februari 2018. Populasi pada penelitian ini yaitu anak di PAUD Bukit Selanjut Kecamatan Kelayang Kabupaten Indragiri Hulu yang berjumlah keseluruhan 13 orang anak, yang diantaranya 6 orang anak kelompok A dan 7 orang anak kelompok B. Sampel yang diambil dalam penelitian ini adalah anak kelompok B yang berjumlah 7 orang anak, terdiri dari 4 orang anak laki-laki dan 3 orang anak perempuan.

Teknik pengumpulan data memakai:

1. Test 
Peneliti membagi tes menjadi 2 yaitu :

a. Pre test, dilakukan sebelum pelaksanaan kegiatan mewarnai gambar, ini untuk mengetahui kemampuan motorik halus anak.

b. Post test, dilakukan sesudah pelaksanaan kegiatan mewarnai gambar, ini untuk mengetahui peningkatan kemampuan motorik halus anak setelah dilakukan tindakan.

2. Observasi

Observasi yang peneliti lakukan ialah dengan pengamatan secara langsung kepada kegiatan mewarnai gambar siswa dan perkembangan motorik halus anak melalui lembar observasi

3. Dokumentasi

Dokumentasi yang dilakukan ialah mengumpulkan foto-foto anak ketika kegiatan mewarnai berlangsung, profil sekolah, sarana dan prasarana.

Teknik analisis data yang digunakan dalam penelitian ini adalah analisis uji-t, untuk melihat pengaruh kegiatan mewarnai gambar terhadap kemampuan motorik halus anak sebelum dan sesudah diberi perlakuan. Rumus yang dipakai adalah seperti berikut:

Uji t (Hitung)

$$
t=\frac{\mathrm{Md}}{\sqrt{\frac{\Sigma X^{2} d}{N(N-1)}}}
$$

Keterangan :

$\mathrm{Md}=$ Mean dari devisiasi (d) antara posttest dan pretest

$\mathrm{Xd}=$ Perbedaan deviasi dengan mean deviasi $(\mathrm{d}-\mathrm{Md})$

$\mathrm{Df}=$ atau db adalah $\mathrm{N}-1$

$\mathrm{N}=$ Banyaknya subjek penelitian

\section{PEMBAHASAN}

Analisis data dilakukan dengan teknik statistik $t$-test dan juga menggunakan bantuan SPSS Windows Ver. 17. Teknik statistik t-test digunakan untuk menguji perbedaan sebelum dan sesudah perlakuan. Tujuan penelitian ini adalah untuk mengetahui Pengaruh Kegiatan Mewarnai Gambar Terhadap Kemampuan Motorik Halus Anak Kelompok B di PAUD Bukit Selanjut Kecamatan Kelayang Kabupaten Indragiri Hulu. Penelitian ini terdiri dari dua tes yaitu pretest dan posttest pada kelompok eksperimen anak kelompok B yang terdiri dari 7 anak.

Tabel I

Deskripsi data hasil penelitian

\begin{tabular}{|c|c|c|c|c|c|c|c|c|}
\hline Variabel & \multicolumn{3}{|c|}{$\begin{array}{c}\text { Skor X dimungkinkan } \\
\text { (Hipotetik) }\end{array}$} & \multicolumn{4}{|c|}{$\begin{array}{c}\text { Skor X yang Diperoleh } \\
\text { (Empirik) }\end{array}$} \\
\hline & $\mathrm{X}$ & $\mathrm{X}$ & Mean & SD & $\mathrm{X}$ & $\mathrm{X}$ & Mean & SD \\
\hline
\end{tabular}




\begin{tabular}{|l|c|c|c|c|c|c|c|c|}
\hline & Min & $\max$ & & & Min & Max & & \\
\hline Pretest & 4 & 16 & 10 & 3 & 8 & 10 & 9.1429 & .89974 \\
\hline Posttest & 4 & 16 & 10 & 3 & 10 & 14 & 13 & .81650 \\
\hline
\end{tabular}

Sumber : Olahan Data Penelitian 2018, Lampiran 7

Berdasarkan tabel di atas, maka dapat dilihat bahwa nilai rata-rata empirik skor kemampuan mengenal konsep bilangan anak meningkat setelah diberikan eksperimen. Ini menandakan bahwa penggunaan kegiatan mewarnai gambar berpengaruh positif untuk meningkatkan kemampuan motorik halus anak.

a. Gambaran umum kemampuan motorik halus anak kelompok B di PAUD Bukit

Selanjut Kecamatan Kelayang Kabupaten Indragiri Hulu dalam kegiatan mewarnai gambar sebelum diberikan perlakuan atau treatment (pretest)

Kegiatan pretest dilaksanakan 1 kali yaitu tanggal 8 Januari 2018. Pelaksanaan pretest bertujuan untuk mengetahui gambaran kemampuan motorik halus anak dalam kegiatan mewarnai gambar sebelum diberikan perlakuan atau treatment. Berdasarkan hasil pretest tersebut maka dapat dilihat bahwa kemampuan kemampuan motorik halus anak kelompok B di PAUD Bukit Selanjut Kecamatan Kelayang Kabupaten Indragiri Hulu dikategorikan rendah, yang mana dapat dilihat pada tabel berikut ini:

Tabel II

Gambaran umum kemampuan motorik halus anak kelompok B di PAUD Bukit Selanjut Kecamatan Kelayang Kabupaten Indragiri Hulu dalam kegiatan mewarnai gambar sebelum diberikan perlakuan atau treatment (pretest)

\begin{tabular}{|c|l|c|c|c|c|}
\hline No & \multicolumn{1}{|c|}{ Indikator } & $\begin{array}{l}\text { Skor } \\
\text { Akhir }\end{array}$ & $\begin{array}{l}\text { Skor } \\
\text { Ideal }\end{array}$ & Kriteria \\
\hline 1 & $\begin{array}{l}\text { Memegang alat untuk mewarnai seperti pensil } \\
\text { warna, spidol warna, crayon, dan alat warna } \\
\text { lainnya } \\
\text { dengan baik dan benar }\end{array}$ & 14 & 28 & 50 & MB \\
\hline 2 & $\begin{array}{l}\text { Menggunakan alat untuk mewarnai seperti } \\
\text { pensil warna, spidol warna, crayon, dan alat } \\
\text { warna lainnya dengan baik dan benar. }\end{array}$ & 17 & 28 & $\begin{array}{c}60,7 \\
1\end{array}$ & BSH \\
\hline 3 & $\begin{array}{l}\text { Menggerakkan tangan dengan lentur saat } \\
\text { mewarnai }\end{array}$ & 14 & 28 & 50 & MB \\
\hline 4 & $\begin{array}{l}\text { Membubuhi atau memberi warna yang benar } \\
\text { sesuai gambar }\end{array}$ & 19 & 28 & $\begin{array}{c}67,8 \\
5\end{array}$ & BSH \\
\hline & Jumlah & 64 & 112 & $\begin{array}{c}228, \\
56\end{array}$ & \\
\hline & Rata-rata & & & $\begin{array}{c}57,1 \\
4\end{array}$ & BSH \\
\hline
\end{tabular}

Sumber: Data Olahan Penelitian 2018, lampiran 5

Berdasarkan tabel diatas dapat diketahui bahwa pada skor akhir tertinggi terdapat pada indikator 4 yaitu anak mampu membubuhi atau memberi warna yang benar sesuai gambar 
dengan skor akhirnya 19, persentase 67,85\% yang berada pada kriteria BSH. Skor akhir terendah terdapat pada indikator 1 dan 3 yaitu memegang alat untuk mewarnai seperti pensil warna, spidol warna, crayon, dan alat warna lainnya dengan baik dan benar dan menggerakkan tangan dengan lentur saat mewarnai dengan skor akhirnya 14 , persentase 50\% yang berada pada kriteria MB.

Untuk mengetahui gambaran kemampuan motorik halus anak kelompok B di PAUD Bukit Selanjut Kecamatan Kelayang Kabupaten Indragiri Hulu dalam kegiatan mewarnai gambar sebelum diberikan perlakuan atau treatment maka dapat dilihat pada tabel dibawah ini:

\section{Tabel III}

\section{Kemampuan motorik halus anak kelompok B di PAUD Bukit Selanjut Kecamatan}

Kelayang Kabupaten Indragiri Hulu dalam kegiatan mewarnai gambar sebelum diberikan perlakuan atau treatment (pretest)

\begin{tabular}{|c|c|c|c|c|}
\hline No. & Kriteria & Rentang Skor & F & $\%$ \\
\hline 1. & BSB & $76-100 \%$ & 0 & 0 \\
\hline 2. & BSH & $56-75 \%$ & 5 & 71,43 \\
\hline 3. & MB & $41-55 \%$ & 2 & 28,57 \\
\hline 4. & BB & $<40 \%$ & 0 & 0 \\
\hline & Jumlah & & 7 & 100 \\
\hline
\end{tabular}

Sumber: Olahan Data Penelitian 2018, Lampiran 5

Berdasarkan tabel diatas maka dapat diketahui bahwa kemampuan motorik halus anak didik dalam kegiatan mewarnai gambar sebelum adanya perlakuan diperoleh data anak yang berada pada kategori BSB sebanyak 0 orang anak dengan persentase $0 \%$, anak yang pada kategori BSH sebanyak 5 orang anak dengan persentase 71,43\%, anak yang berada pada kategori MB sebanyak 2 orang anak dengan persentase 28,57\%, anak dengan kategori BB sebanyak 0 anak dengan persentase $0 \%$. Untuk lebih jelas dapat dilihat pada grafik berikut ini:

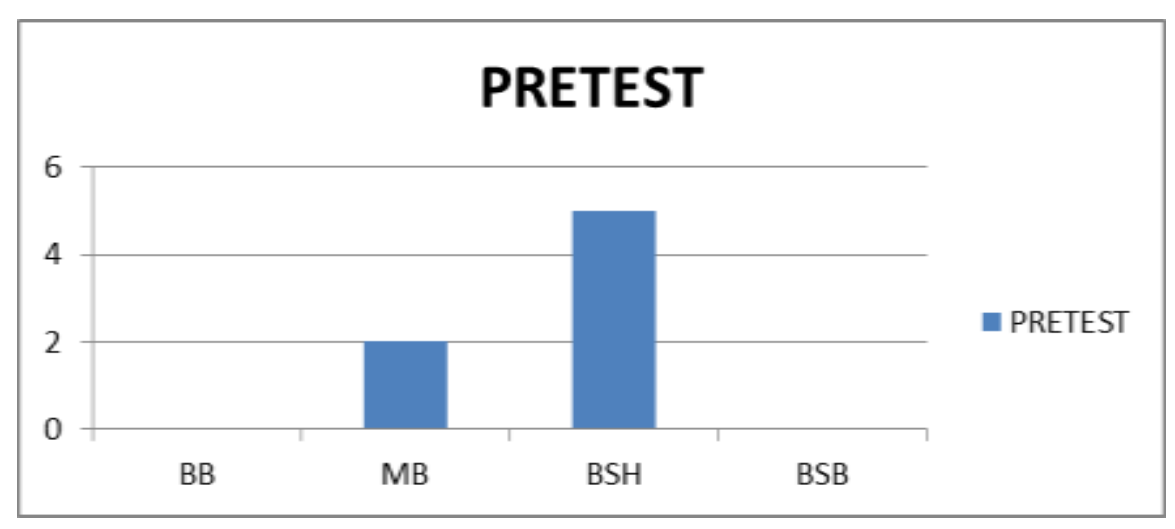

Gambar I. Diagram kemampuan motorik halus dalam bidang mewarnai gambar sebelum perlakuan (pretest) 
b. Gambaran umum kemampuan motorik halus anak kelompok B di PAUD Bukit Selanjut Kecamatan Kelayang Kabupaten Indragiri Hulu dalam kegiatan mewarnai gambar sesudah diberikan perlakuan atau treatment (posttest)

Penelitian selanjutnya dengan memberikan treatment pada kegiatan mewarnai gambar, yang mana pada penelitian ini peneliti sebagai pemateri pemberi treatment. Kegiatan pemberian perlakuan (treatment) diberikan pada 9, 10, 11, 12, 15, 16, 17, dan 18 Januari 2018. Kemudian kegiatan posttest dilaksanakan pada 19 Januari 2018. Untuk mengetahui gambaran kemampuan motorik halus dalam bidang mewarnai gambar anak setelah diberi perlakuan (treatment) maka dapat dilihat pada tabel di bawah ini:

\section{Tabel IV}

Gambaran umum kemampuan motorik halus anak kelompok B di PAUD Bukit Selanjut Kecamatan Kelayang Kabupaten Indragiri Hulu dalam kegiatan mewarnai gambar sesudah diberikan perlakuan atau treatment (posttest)

\begin{tabular}{|c|c|c|c|c|c|}
\hline No & Indikator & $\begin{array}{l}\text { Skor } \\
\text { Akhir }\end{array}$ & $\begin{array}{l}\text { Skor } \\
\text { Ideal }\end{array}$ & $\%$ & Kriteria \\
\hline 1 & $\begin{array}{l}\text { Memegang alat untuk mewarnai seperti } \\
\text { pensil warna, spidol warna, crayon, dan alat } \\
\text { warna lainnya dengan baik dan benar }\end{array}$ & 24 & 28 & 85,71 & BSB \\
\hline 2 & $\begin{array}{l}\text { Menggunakan alat untuk mewarnai seperti } \\
\text { pensil warna, spidol warna, crayon, dan alat } \\
\text { warna lainnya dengan baik dan benar. }\end{array}$ & 21 & 28 & 75 & $\mathrm{BSH}$ \\
\hline 3 & $\begin{array}{l}\text { Menggerakkan tangan dengan lentur saat } \\
\text { mewarnai }\end{array}$ & 21 & 28 & 75 & $\mathrm{BSH}$ \\
\hline 4 & $\begin{array}{l}\text { Membubuhi atau memberi warna yang } \\
\text { benar sesuai gambar }\end{array}$ & 25 & 28 & 89,28 & BSB \\
\hline \multicolumn{2}{|r|}{ Jumlah } & 91 & 112 & 324,99 & \\
\hline & Rata-rata & & & 81,2475 & BSB \\
\hline
\end{tabular}

Sumber: Data Olahan Penelitian 2018, Lampiran 6

Berdasarkan tabel diatas dapat diketahui bahwa pada skor akhir tertinggi terdapat pada indikator 4 yaitu anak mampu membubuhi atau memberi warna yang benar sesuai gambar dengan skor akhirnya 25 , persentase $89,28 \%$ yang berada pada kriteria BSB. Skor akhir terendah terdapat pada indikator 2 dan 3 yaitu menggunakan alat untuk mewarnai seperti pensil warna, spidol warna, crayon, dan alat warna lainnya dengan baik dan benar dan menggerakkan tangan dengan lentur saat mewarnai dengan skor akhirnya 21 , persentase $75 \%$ yang berada pada kriteria BSH.

Untuk mengetahui gambaran kemampuan motorik halus anak kelompok B di PAUD Bukit Selanjut Kecamatan Kelayang Kabupaten Indragiri Hulu dalam kegiatan mewarnai gambar sesudah diberikan perlakuan (treatment) maka dapat dilihat pada tabel dibawah ini: 


\section{Tabel V}

Kemampuan motorik halus anak kelompok B di PAUD Bukit Selanjut Kecamatan

Kelayang Kabupaten Indragiri Hulu dalam kegiatan mewarnai gambar sesudah diberikan perlakuan atau treatment (posttest)

\begin{tabular}{|c|c|c|c|c|}
\hline No. & Kriteria & Rentang Skor & F & $\mathbf{\%}$ \\
\hline 1. & BSB & $76-100 \%$ & 5 & 71,43 \\
\hline 2. & BSH & $56-75 \%$ & 2 & 28,57 \\
\hline 3. & MB & $40-55 \%$ & 0 & 0 \\
\hline 4. & BB & $<40 \%$ & 0 & 0 \\
\hline & Jumlah & & 7 & 100 \\
\hline
\end{tabular}

Sumber: Olahan Data Penelitian 2018, Lampiran 6

Berdasarkan tabel diatas maka dapat diketahui bahwa kemampuan motorik halus anak didik dalam kegiatan mewarnai gambar sesudah adanya perlakuan diperoleh data anak yang berada pada kategori BSB sebanyak 5 orang anak dengan persentase $71,43 \%$, anak yang pada kategori BSH sebanyak 2 orang anak dengan persentase 28,57\%, dan tidak terdapat anak didik yang berada pada kategori $\mathrm{MB}$ dan $\mathrm{BB}$ atau $0 \%$. Untuk lebih jelas dapat kita lihat pada grafik berikut ini:

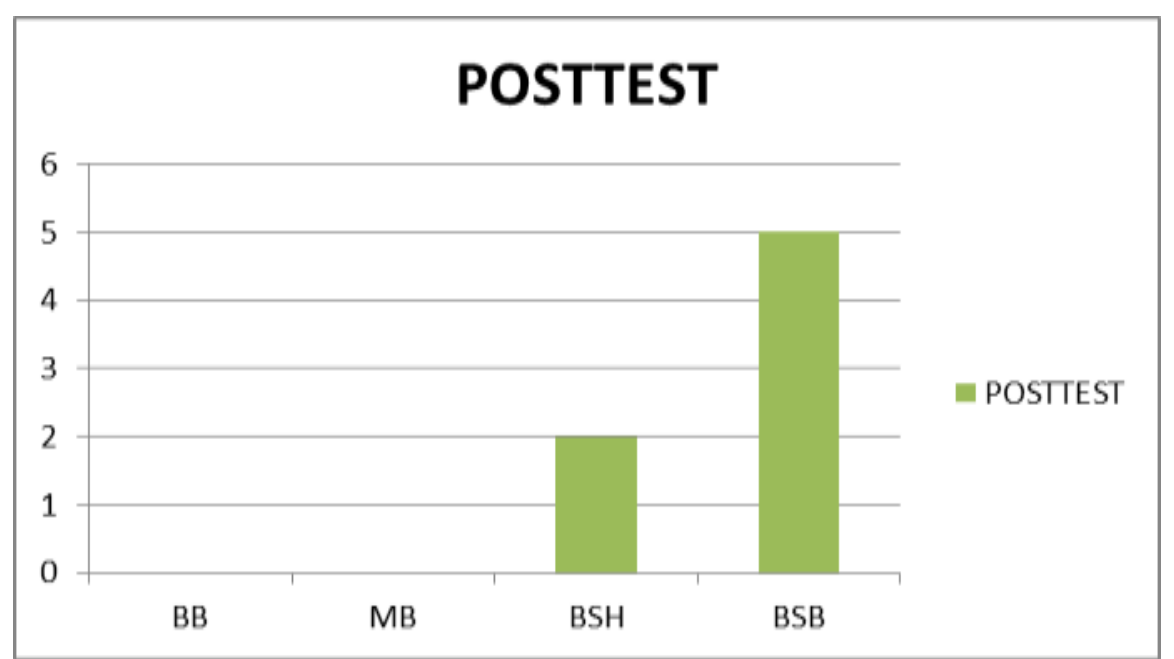

Gambar II. Diagram kemampuan motorik halus dalam bidang mewarnai gambar sesudah perlakuan (posttest)

\section{c. Perbandingan data Pretest dan Posttest}


Penelitian ini dilakukan menggunakan one group pretest posttest design yaitu melihat hasil pretest dan posttest. Adapun hasil pretest dan posttest dapat dilihat pada tabel di bawah ini :

\section{Tabel VI}

\section{Rekapitulasi kemampuan motorik halus anak sebelum dan sesudah diberi perlakuan} dalam kegiatan mewarnai gambardi PAUD Bukit Selanjut Kecamatan Kelayang Kabupaten Indragiri Hulu

\begin{tabular}{|l|c|c|c|c|c|c|}
\hline \multirow{2}{*}{ No } & \multirow{2}{*}{ Kategori } & \multirow{2}{*}{ Rentang Skor } & \multicolumn{2}{|c|}{ Sebelum } & \multicolumn{2}{|c|}{ Sesudah } \\
\cline { 4 - 7 } & & & F & $\%$ & F & $\%$ \\
\hline 1. & BSB & $76-100 \%$ & 0 & 0 & 5 & 71,43 \\
\hline 2. & BSH & $56-75 \%$ & 5 & 71,43 & 2 & 28,57 \\
\hline 3. & MB & $41-50 \%$ & 2 & 28,57 & 0 & 0 \\
\hline 4. & BB & $<40 \%$ & 0 & 0 & 0 & 0 \\
\hline
\end{tabular}

\section{Sumber: Olahan Data Penelitian 2018, Lampiran 5 dan 6}

Berdasarkan Tabel VI perbandingan sebelum dan sesudah perlakuan diatas dapat diketahui bahwa sebagian besar anak yang telah diberikan perlakuan (treatment) mengalami peningkatan. Anak yang awalnya berada pada kriteria BSB sebanyak 0 orang anak dengan presentase $0 \%$, anak yang pada kriteria BSH sebanyak 5 orang anak dengan persentase $71,43 \%$, anak yang berada pada kriteria MB sebanyak 2 orang anak dengan persentase 28,57\%, anak dengan kriteria $\mathrm{BB}$ sebanyak 0 anak dengan persentase $0 \%$. Kemudian terjadi peningkatan menjadi anak yang berada pada kriteria BSB sebanyak 5 orang anak atau 71,43\% yang berada pada kriteria BSH sebanyak 2 orang anak atau 28,57\%, dan tidak terdapat anak yang berada pada kriteria $\mathrm{MB}$ dan $\mathrm{BB}$ atau $0 \%$. Untuk lebih jelas dapat dilihat pada gambar berikut:

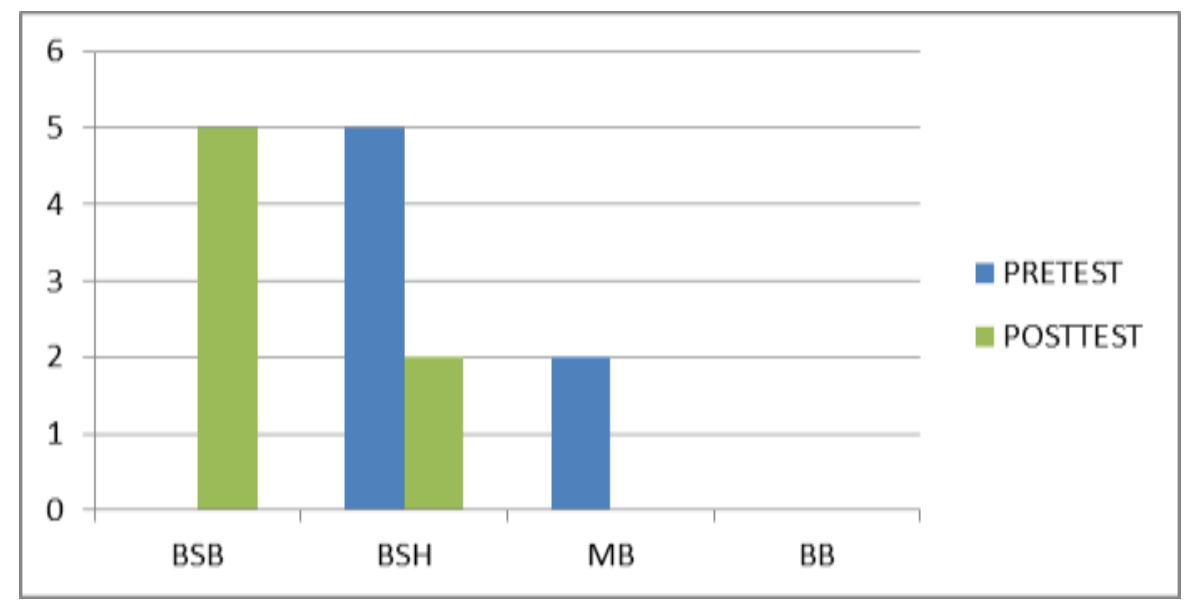


Gambar III. Diagram kemampuan motorik halus pretest dan posttest

\section{KESIMPULAN}

Berdasarkan hasil pengujian dan penelitian yang dilakukan di PAUD Bukit Selanjut Kecamatan Kelayang Kabupaten Indragiri Hulu tentang Pengaruh Kegiatan Mewarnai Gambar Terhadap Kemampuan Motorik Halus Anak Kelompok B, maka dapat disimpulkan ada Pengaruh yang Signifikan. Yang mana hasil pengujian hipotesis menunjukkan bahwa hipotesis penelitian ( $\mathrm{Ha}$ ) yang diajukan dalam penelitian ini diterima, hasil penelitian menunjukkan bahwa $t_{\text {hitung }} 27,000$ dengan nilai Sig. $0,000<0,05 . t_{\text {hitung }}=27,000$ lebih besar dari $t_{\text {tabel }}=2,447$. Dengan demikian Ho ditolak dan Ha diterima. Dan adapun besar pengaruhnya sebesar 56,25\% yang berada pada kategori sedang.

\section{REFERENSI}

Al-Qur'an dan Terjemahan. Syaamil Qur'an. Bandung: Departemen Agama.

Ardy Wiyani Novan. 2014. Psikologi Perkembangan Anak Usia Dini Panduan Bagi Orang Tua dan Pendidik PAUD Dalam Memahami Serta Mendidik Anak Usia Dini. Yogyakarta: Gava Media.

Arikunto Suharsimi. 2010. Prosedur Penelitian Suatu Pendekatan Praktik. Jakarta: Rineka Cipta.

Ayu Aristyadewi Ni Made, dkk, Penerapan Metode Pemberian Tugas Melalui Kegiatan Menggambar Dekoratif Media Krayon Untuk. Meningkatkan Kemampuan Motorik. Halus, (Volume 3 No.1 Tahun 2015), E-Journal PG PAUD Universitas Pendidikan Ganesha Jurusan Pendidikan Guru Pendidikan Anak Usia Dini.

Beal Nancy dan Gloria Bley Miller. 2003. Rahasia Mengajar Seni Pada Anak di Sekolah dan di Rumah. Penerjemah: Fretty H. Pangabean. Yogyakarta: Futuh Printika.

D. Tilong Adi. 2016. 49 Aktivitas Pendongkrak Kinerja Otak Kanan dan Kiri Anak. Yogyakarta: Laksana.

Decaprio Richard. 2013. Aplikasi Teori Pembelajaran Motorik di Sekolah. Jogjakarta: Diva Press.

Dimyati Johni. 2013. Metodologi Penelitian Pendidikan dan Aplikasinya Pada Pendidikan Anak Usia Dini (PAUD). Jakarta: PT Fajar Interpratama Mandiri.

Endang Susilowati Siti. NIM. A53I130049. 2015. Peningkatan Kemampuan Motorik Halus Melalui Kegiatan Mewarnai Gambar Pada Kelompok. A TK Pertiwi Bergolo. Pdf.

Fadhilah Nurul, NIM 10111244028. 2014. Meningkatkan Kemampuan Motorik Halus Melalui Kegiatan Mewarnai di Kelompok B TK Kklkemd Sedyo Rukun Bambanglipuro Bantul. Pdf.

http://www.e-jurnal.com/2014/01/faktor-faktor yang mempengaruhi motorik. html 
Ikhwani Syaputri Hesty. NIM 1305113419. 2017. Pengaruh Media Stick Puppets Terbadap Kemampuan Mengenal Konsep Bilangan Anak Usia 5-6 Tabun di TK Al-Fajar Kecamatan Tampan Kota Pekanbaru. Pdf.

Indraswari Lolita, Jurnal Pesona PAUD Vol.1.No.1, email: lolita.Indraswari@gmail.com.

Pamilu Anik. 2008. Mengoptimalkan Keajaiban Otak Kanan dan Otak Kiri Anak. Magelang: Pustaka Horizona.

Peraturan Menteri Pendidikan dan Kebudayaan, No 137, Tahun 2014, Standar Tingkat Pencapaian Kemampuan Anak Usia 5-6 Tahun Dalam Lingkup Perkembangan Motorik Halus.

Peraturan Menteri Pendidikan Nasional Republik Indonesia, Nomor 58 Tabun 2009, Lingkup Perkembangan Motorik Dalam Bidang Motorik Halus Anak Usai 5-6 Tahun.

Sri Murdiani Niluh, Pengarub Kegiatan Mewarnai Gambar Dalam meningkatkan Motorik. Halus Anak Di Kelompok B Tk Jaya Kumara Desa Balinggi Jati Kecamatan Balinggi Kabupaten Parigi Moutong, Pdf.

Sudaryono, dkk. 2013. Pengembangan Instrumen Penelitian Pendidikan. Yogyakarta: Graha Ilmu.

Sugioyono. 2010 Metode Penelitian Pendidikan Pendekatan Kuantitatif, Kualitatif, Dan R\&D. Bandung: Alfabeta.

Sumantri Ms. 2005. Model Pengembangan Keterampilan Motorik. Anak Usia Dini. Jakatra: Departemen Pendidikan Nasional.

Yaumi Muhammad dan Nurdin Ibrahim. 2013. Pembelajaran Berbasis Kecerdasan Jamak(Multiple Intelligences). Jakarta: Kencana. 